\title{
Empirical Analysis of Rural Citizens' Political Participation in the Underdeveloped Regions of Chinese Eastern Provinces
}

\author{
Zhenjun Mao \\ Department of Politics and Law, Dezhou University \\ Dezhou 253012, China \\ E-mail: maozhenjun@126.com
}

\begin{abstract}
The rural citizens' political participation case of Xiaohe Village in Dezhou City of Shangdong Province indicates that in the underdeveloped rural regions of Chinese eastern provinces, rural citizens' political participation has the characters such as the participation enthusiasm and organization degree are lower, the political participation degree and level are lower, and the probability of the non-systemization of political participation still exists. Only to enhance the rural citizens' income, establish and perfect various political mechanisms, strengthen rural citizens' comprehensive quality, reform and extend various political participation channels to satisfy rural citizens' practical demands, the ordered development of rural citizens' political participation could be drove powerfully.
\end{abstract}

Keywords: Underdeveloped regions, Rural citizens, Political participation, Political mechanism

In the monograph of "Democracy Mode", British scholar, David Held pointed out that "When citizens have a series of political participations and regard the political participation as a kind of right, the democracy is the democracy being worthy of the name". Therefore, the political participation embodies the essential of the democratic politics, and it is the base that the modern social democracy system survives. Because the rural citizens of China occupy the most of total citizens, the importance of rural citizens' political participation speaks for itself. Of course, rural citizens' ability and level of political participation is closely related with the economic development degree in their regions. Generally speaking, the economic development is positively correlated with the degree of political participation (Wang, 1995, P.221). Taking the rural citizens' political participation case of Xiaohe Village in Dezhou City of Shangdong Province as an example, this research tries to draw the outline of the practical picture of rural citizens' political participation and the political ecology of rural democratic politics construction in the underdeveloped regions of Chinese eastern provinces.

\section{The basic situation of citizens' political participation in Xiaohe Village}

The questionnaire survey was implemented in the Xiaohe Village of Dezhou City. In the questionnaire survey, 120 adult villages of Xiaohe Village were surveyed by the grading-sampling method, and 120 effective questionnaires were returned, and in addition, some common citizens and cadres of Xiaohe Village were visited stochastically.

\subsection{Political voting}

Political voting is a kind of political behavior that the individual citizen shows his political favor or political attitude before competitive policies or candidates or other disputable political problems (Hou, 2006). The proportion that adult citizens in Xiaohe Village voted was not high. When they were asked whether they voted often, only one third of them said yes, and most of them voted for the village cadres. And when they were asked whether they wanted to participate in the election, many citizens said no.

Citizens in Xiaohe Village had few passions for the election of NPC (National People's Congress) members. Someone even didn't know how the NPC members were elected, and didn't know they had the right to the elect NPC members. When they were asked whether they would to elect NPC members, about three fourth of them thought that was meaningless, and didn't want to go.

\subsection{Political contact}

Political contact means that citizens formally or informally disclose information or put forward opinions, advices, or comments to cadres by the individual mode or the collective mode in order to influence or change their 
decisions. The contact generally includes the reflection, appealing to the higher authorities for help, and bribe. Few of citizens in Xiaohe Village contacted with cadres, and most of citizens didn't think the contact with cadres was a main political participation means. In their eyes, even to see the leader could act nothing, so the contact was not the best method to solve problems. In the survey statistics, $60 \%$ of surveyed citizens said they could not contact with cadres at all, so they have not the intention of contact, and only $5 \%$ of them said it was easy to contact with cadres (seen in Table 1). It is obvious seen that some cadres broke away from citizens in their works, so when villagers faced difficulties, they would first think of their families and friends, not the superior cadres (seen in Table 2).

The Xiaohe Village citizens' consciousness of appealing to the higher authorities for help changed to weak from strong. In the past, because of various causes, the political participation mode adopted by Chinese rural citizens was to appeal to the higher authorities for help, so was Xiaohe Village's citizens. $45 \%$ of citizens in Xiaohe Village had the experiences or ideas to appeal to the higher authorities for help, and the problems mainly centralized in too heavy burdens, and a few cadres' corruption. Most citizens thought that to appeal to the higher authorities for help was forced. In recent years, because the government continually reduced rural citizens' burdens and strengthen the anti-corruption power, many problems puzzling rural citizens have been gradually solved, and rural citizens' consciousness of appealing to the higher authorities for help has changed to weak from strong, and near $85 \%$ of surveyed citizens' in Xiaohe Village showed that they had not the experiences or ideas to appeal to the higher authorities for help in recent years.

\subsection{Political expression}

In the villages of China, the modes of political expression mainly include appeal and lawsuit. The appeal means that citizens utilize the consensus tools to indirectly implement the political participation. Many citizens in Xiaohe Village used the appeal, and 30\% of them had the experience of appeal for the compensation for requisition of land, cadres' denial of justice, and children's enrollment in school. The survey showed that $65 \%$ of citizens thought that the appeal didn't work, but $35 \%$ of citizens would use this mode to solve problems. In addition, few citizens in Xiaohe Village used the appeal to solve problems. And $95 \%$ of citizens in Xiaohe Village thought they would not win in the lawsuit with the government.

\section{Characters of Citizens' political participation in Xiaohe Village}

\subsection{The enthusiasm and organization degree of political participation are lower}

The active participation means that the participation objects actively and spontaneously participate in the politics, and the passive participation means the political participation under others' mobilization or threat. Obviously, the active participation indicates that the participation objects have strong political performance sense, not the passive participation. Xiaohe Village citizens' political participation could obviously reflect the character of passive participation. In the citizens who participated in the village election, $48.4 \%$ of them were required to participate in the election by the village party committee, and $31.7 \%$ of them solicited votes for their relations and friends, and $5.8 \%$ of them joined in the fun, and the total proportion of these three voters achieved $85.9 \%$, and only 14.2 of them voted for "their own rights", "election is related with their own benefits", and "want to elect the best leader" (seen in Table 3). The Xiaohe Village's citizens' political participation was mainly because of the requirement of the village party committee or others' mobilization, and few citizens could feel the performance sense.

Individual participation is comparative with the organized participation. Generally speaking, the organized participation is more effective than the individual participation and its effect and degree is higher than the individual participation. On certain meaning, the organized participation could reflect the benefit and performance of the political participation, and it is the form of political participation on higher level. Almost all Xiaohe Village citizens' political participations belong to individual participation. And most of them participate in the election or appeal independently, without elites' mobilization or organization, and most of them had not the idea to be organized to participate in the politics.

\subsection{The degree and level of political participation are lower}

Totally speaking, Xiaohe Village's citizens' political participation degree and level were still lower. First, though someone participated in the election and other political activities, but their frequency and times of political participation were not high. But in the developed rural regions, the proportion that rural citizens often participate in the election of village party committee has exceeded 90\% (Shi, 1999, P.47), but in Xiaohe Village, this proportion was only $35 \%$. Second, fewer citizens had the consciousness of political participation and often participated in the political activities. As viewed from the statistics of survey, many villagers didn't not their 
behaviors were political participation in many cases in Xiaohe Village, and they only participated in the political activities unconsciously, and they had not regarded the political participation as their own rights and obligations, and the level of political participation was lower. Third, Xiaohe Village citizens' political participation was basically limited in the problem-type participation, and only when their own benefits were impinged, they would protect their own concrete benefits, which belonged to the passive problem-type participation.

\subsection{The probability of the non-systemization of political participation still exists}

System is the game law of the society, and it includes the formal system and informal system. The activities of political participation in the formal system frame can be called as the system-type participation, and the activities of political participation exceeding the existing system frame are called as the non-system-type participation. In recent years, the non-system-type participation in rural regions of China often happened, such as greasing the hand of village cadres, and retaliating village cadres even attacking tipstaffs. The system construction of rural regions was weak originally, and rural citizens' legal consciousness was relatively feeble, and the non-system-type participation will destroy the organization construction of villages. Though Xiaohe Village citizens' political participation basically belonged to the system-type participation, and most citizens opposed the violent participation, but someone still understood even supported the violent participation. Therefore, the harms of non-system-type participation should be fully cognized.

\section{Measures to push rural citizens' political participation in the underdeveloped regions of Chinese eastern provinces}

\subsection{Try to enhance rural citizens' income level}

Huntington thought that "in the history, the social-economic modernization seems to hand in hand with political participation, and the development level of society and economy is higher, and the level of political participation is higher also" (Samuel P. Huntington \& John Nelson, 1989, P.46 \& 47). The survey indicated that the difficult maintenance and solution of survival was one important cause to induce a few rural citizens' non-system-type participation. Therefore, on the one hand, various governments must support rural poor citizens from various aspects, and based on that, the government could giver certain policy incline for rural poor citizens' life and production, for example, specially constituting the national security system to improve rural poor citizens' economic status. On the other hand, the village party committee must continually provide supports and create various advantageous conditions for those low-income rural citizens to increase incomes and become rich, such as actively expanding the labor export, and transferring rural surplus labor forces.

\subsection{Establish and perfect various political mechanisms}

First, the village party committee members' total quality should be enhanced, and relative measures include perfecting the mechanism about the periodic training, examination, rewards, punishment, and promotion of the members of village party committee, and continually strengthening their responsibility consciousness, legal consciousness, and service consciousness. Second, the political participation channels should be free continually. At present, part rural citizens want to express and strive for benefits from the channels out of system, because the political system which could contain multiple benefit requirements is deficient, so the system-type political participation will fail. So the adaptability, cohesion, and independence of rural community political system should be enhanced properly when developing the political participation, for example, the villager decision-making system, the discussion system, and the democratic evaluation system should be further perfected. Third, the system level of rural community information channel must be further enhanced. The practice has proved that if the information channel is deficient or the systemization degree is lower, the non-system-type participation not only may but will be a kind of pernicious accumulation. Therefore, various modes should be explored to enhance the systematization degree of the rural community information channel, such as continually making the village affairs more transparent, and further strengthening the transparency of the village affair management.

\subsection{Continually strengthen rural citizens' comprehensive quality}

"Knowledge is the political resource to help forming the political skills (Robert Berdahl, 1987, P.94)". "One person's education degree is higher, the probability that he participates in the political activity is higher, and his attitude about the political problems is more firm, and he will hold more enlightened, free, or flexible opinions for social cultures and foreign polices (Michel Crozier, 1989, P.97)". At present, rural citizens' non-system-type political participation is decided by the lower total quality to large extent, but the political socialization is one of important measures to enhance the cultural quality and promote the formation of good political psychology. In recent years, relative departments of Dezhou government organized various political drumbeating and political 
mobilizations such as developing various activities of eliminating illiteracy, and science and technology trainings, but the effect of these activities was not ideal. Therefore, based on above activities, new modes should be explored continually, for example, relative departments could periodically organize some experts who research the "issues of agriculture, farmer and rural area" to enter the villages to give various lectures, and these lectures could mainly centralize in following contents, i.e. (1) drumbeating of important laws and regulations about rural citizens' political participation, such as organizing rural citizens to study the "Organic Law of the Villagers Committees of the People's Republic of China", (2) important political knowledge and political skills, such as helping rural citizens to know the basic procedures and rules of various supervision modes.

\subsection{Reform and extend the political participation channels to satisfy rural citizens 'practical demands}

The current political participation out of rural citizen system even illegal political participation doesn't accord with the basic requirements of the modernization and legalization of state, but the relative responsibilities should not be completely undertook by rural citizens, and the essential cause is that the system reform is lagged after the requirements of the practice development. For a long term, rural citizens' appeals and a series of group events were all the result that the existing participation channels could not fulfill rural citizens' requirements of political participation. Just as the state could bring the private enterprises into the systemized participation channel, the state should expand and standardize various channels that rural citizens participate in the state and society life by the reform and legislation. To ensure the order and efficiency of rural citizens' political participation, the state could allow and support rural citizens to found the peasant organizations to maintain their own benefits in the range of laws, which could not only strengthen rural citizens' power in the benefit game with various classes, and orderly participate in the political life of the state, but also reduce the costs of rural citizens' political participation, national governance, and social integration.

\section{References}

Hou, Tiehu \& Huang, Zhaocai. (2006). Research of Rural Citizens' Political Participation in the Construction of New Country. Theoretical Exploration, No. 2.

Michel Crozier \& Samuel P. Huntington. (1989). Crisis of Democracy. Beijing: Qiushi Press, P.97.

Robert Berdahl. (1987). Modern Politics Analysis. Shanghai: Shanghai Translation Publishing House, P.94.

Samuel P. Huntington \& John Nelson. (1989). Difficult to Choose: The Political Participation in Developing Countries. Beijing: Huaxia Press, P.46 \& 47.

Shi, Weimin. (1999). Direct Election: System and Process. Beijing: China Social Sciences Press, P.47.

Wang, Puqu. (1995). Base of Politics. Beijing: Peking University Press, P.221. 
Table 1. Statistical data of citizens' political contact in Xiaohe Village

\begin{tabular}{|l|l|l|}
\hline Contact & Number & Proportion \\
\hline Contact easily & 6 & $5 \%$ \\
Contact only by certain efforts & 18 & $15 \%$ \\
Hard to contact, but with the intention of contact & 24 & $20 \%$ \\
Without not contact and the intention of contact & 72 & $60 \%$ \\
\hline Total & & \\
\hline
\end{tabular}

Table 2. Statistical data of citizens' appeal objects in Xiaohe Village

\begin{tabular}{|l|l|l|}
\hline Appeal objects & Number & Proportion \\
\hline Families & 62 & $51.7 \%$ \\
Friends & 33 & $27.5 \%$ \\
Teachers & 18 & $15 \%$ \\
Village party committee & 5 & $4.1 \%$ \\
Superior government & 2 & $1.7 \%$ \\
\hline Total & & \\
\hline
\end{tabular}

Table 3. Statistical data of citizens' election causes in Xiaohe Village

\begin{tabular}{|l|l|l|}
\hline Causes & Number & Proportion \\
\hline Election is their own rights & 4 & $3.3 \%$ \\
Election is related with their own benefits & 6 & $5 \%$ \\
Want to elect the best leader & 7 & $5.8 \%$ \\
The village party committee requires to participate in the & 58 & $48.4 \%$ \\
election & 38 & $31.7 \%$ \\
Soliciting votes for their relations and friends & 7 & $5.8 \%$ \\
Join in the fun & 120 & $100 \%$ \\
\hline Total & & \\
\hline
\end{tabular}

